\title{
Treatment of Surgical Neck Nonunions of the Humerus with Locked Plate and Autologous Fibular Strut Graft
}

\author{
Kanda Gao Wei Gao Jianhua Huang Xiaoming Wu Chuan Shun Wang \\ Qiugen Wang \\ Department of Orthopedics, Shanghai First People's Hospital, Shanghai Jiaotong University, Shanghai, P.R. China
}

\section{Key Words \\ Proximal humeral nonunion $\cdot$ Locked plate $\cdot$ Bone graft}

\begin{abstract}
Objectives: To determine whether using a fixed-angle locked plate plus a fibular strut autograft to treat humeral surgical neck nonunions can result in improved union. $\mathbf{P a -}$ tients and Methods: The study cohort included 5 females and 2 males with an average age of 58.4 years (range $45-76$ ) who presented with atrophic nonunion of the surgical neck of the humerus. All patients underwent revision surgery with locked plating plus a nonvascularized autologous fibular strut bone graft. Clinical and radiological union was documented in all patients. Results: The mean time from initial trauma to last revision surgery was $20.1 \pm 12.6$ months (range 12-48). The average time between revision surgery and the date of union was 6.1 months (range 5-8). The average active forward flexion was $124^{\circ}$ (range 70-160) at final follow-up. The Constant-Murley score increased from an average of 25.7 points preoperatively to 77.7 points postoperatively $(p<0.001)$. The average analog scale of pain decreased from 7.57 points (range 6-10) preoperatively to 0.57 points (range $0-2$ ) postoperatively $(p<0.001)$. Conclusions: Locked plate fixation and autologous fibular strut bone graft facilitated the successful treatment of humeral surgical neck nonunions.

Copyright $\odot 2012$ S. Karger AG, Basel
\end{abstract}

\section{Introduction}

Surgical neck nonunion is difficult to treat because the proximal fragment is small and difficult to secure, especially when the condition is long-standing nonunion [1]. In addition, neck nonunion is often associated with poor bone quality and compromised soft tissue due to multiple previous surgeries. These factors complicate treatment and pose a significant challenge to surgeons who treat this condition.

Although many treatment options have been described, outcomes have been variable and no definitive surgical solution has been identified [2-7]. The purpose of this retrospective study was to assess the outcomes of locked plating fixation and an autologous nonvascularized fibular strut graft to humeral surgical neck nonunions.

\section{Patients and Methods}

Between January 2006 and March 2010, 7 patients (table 1) with aseptic humeral surgical neck nonunions were treated at our trauma center; the same team supplemented internal fixation with a nonvascularized fibular strut bone graft. All cases were graded as atrophic nonunions according to Weber and Cech's classification [8]. All cases presented with varying degrees of humeral head varus malpositioning.

\section{KARGER}

Fax +4161306 1234

E-Mail karger@karger.ch

www.karger.com
(C) 2012 S. Karger AG, Basel

$1011-7571 / 12 / 0215-0483 \$ 38.00 / 0$

Accessible online at:

www.karger.com/mpp
Qiugen Wang

Department of Orthopedics, Shanghai First People's Hospital

Shanghai Jiaotong University, 100 Haining Road, Hongkou District

Shanghai 200080 (P.R. China)

Tel. +861304563 8862, E-Mail wangqiugen@126.com 
Fig. 1. a 'Interdigitated' fibular graft placement with reduction of the humeral head on the shaft. b Final fixation with fixedangled locked plate and passage of screws through the graft.
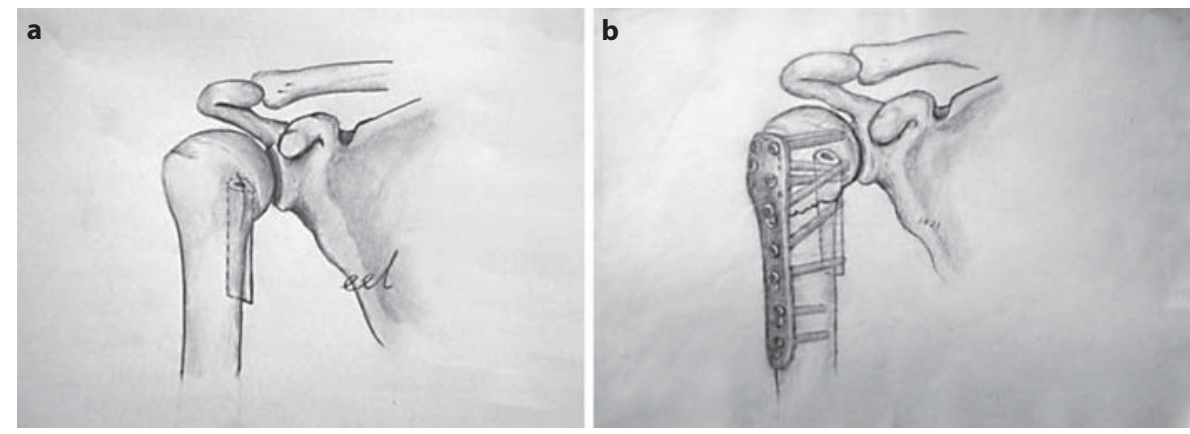

Table 1. Patient characteristics

\begin{tabular}{|c|c|c|c|c|c|c|}
\hline $\begin{array}{l}\text { Patient } \\
\text { No. }\end{array}$ & Age/sex & Mechanism & $\begin{array}{l}\text { Dominant } \\
\text { arm }\end{array}$ & Previous treatment & Comorbidities & $\begin{array}{l}\text { Delay from injury to } \\
\text { operation, months }\end{array}$ \\
\hline 1 & $46 / \mathrm{F}$ & fall & no & common plate and locked plate & none & 48 \\
\hline 2 & $53 / \mathrm{M}$ & fall & yes & $\mathrm{K}$-wires and staple & smoker & 20 \\
\hline 3 & $57 / \mathrm{F}$ & traffic accident & yes & clover plate & none & 12 \\
\hline 4 & $72 / \mathrm{F}$ & fall & no & sling & osteoporosis, hypertension & 16 \\
\hline 5 & $76 / \mathrm{F}$ & fall & no & sling & $\begin{array}{l}\text { diabetes, hypertension, } \\
\text { osteoporosis }\end{array}$ & 12 \\
\hline 6 & $44 / \mathrm{M}$ & traffic accident & yes & cloverleaf plate & none & 18 \\
\hline 7 & $61 / \mathrm{F}$ & fall & no & cloverleaf plate & none & 15 \\
\hline
\end{tabular}

The 7 patients comprised 5 females and 2 males with an average age of 58.4 years (range $45-76$ ). The right dominant arm was affected in 3 cases and the left non-dominant arm in 4 cases. All nonunions resulted from traumatic fractures. The initial fractures were secondary to falls from a standing height in 5 cases and car accidents in 2 cases. The time from initial fracture to repair of the nonunion with internal fixation and fibular strut graft ranged from 10 to 48 months with an average of 20 months (table 1).

\section{Operative Techniques}

The patients were operated on in the beach chair position while under general anesthesia. The shoulders and ipsilateral legs were prepared and draped at the same time. A standard deltopectoral approach was used to expose the nonunion site of the surgical neck of the humerus. The implants were removed from 5 patients who had failure of hardware. Then the interposing scar and fibrous tissue were meticulously debrided and tissue samples were collected for culture to exclude any occult infections. The humeral head varus deformity was corrected in all patients and the locations of the bone defects were noted. In each patient, a 5-6 cm fibula was harvested from the ipsilateral leg through osteotomy and was applied on the medial cortex of the humerus. The cephalad portion of the graft was impacted into the cancellous bone of the head (fig. 1a). An internal fixation with humeral proximal locked plate (Synthes) was applied to all patients. The fibula graft was fixed with at least two screws at the caudal portion, leaving an approximately $1-2 \mathrm{~cm}$ cephalad part onto which the humeral head was impacted (fig. 1b). No attempt was made to pass the proximal screws through the fibular graft.

\section{Postoperative Management}

In all cases, patients' shoulders were immobilized postoperatively for 6 weeks using a sling. Therapists initiated a passive range of movement exercises on the first operative day and started a progressive range of movements at 3 weeks. Follow-up reviews were made monthly at the outpatient clinic until the fracture had healed. Radiological union was defined as bridging bone trabecula across the fracture site and incorporating the fibula graft into the humeral shaft. Each patient was assessed for pain, shoulder mobility, and strength at each follow-up using the Constant-Murley score and a visual analog scale (VAS). To test for differences between the preoperative and postoperative Constant-Murley score and the analog pain scale, a statistical analysis was performed with Fisher's test using SPSS 11.0 statistical software (Chicago, Ill., USA). A p value $<0.05$ was considered statistically significant.

\section{Results}

The mean length of follow-up was $22.7 \pm 6.5$ months (range 15-36). All patients achieved clinical and radiological union and none required any additional procedures (fig. 2a-f). The mean time from revision surgery to union was $6.1 \pm 1.3$ months (range 5-8).

The average active forward flexion was $124^{\circ}$ (range 70 160 ), average active abduction was $119^{\circ}$ (range $70-160$ ), 

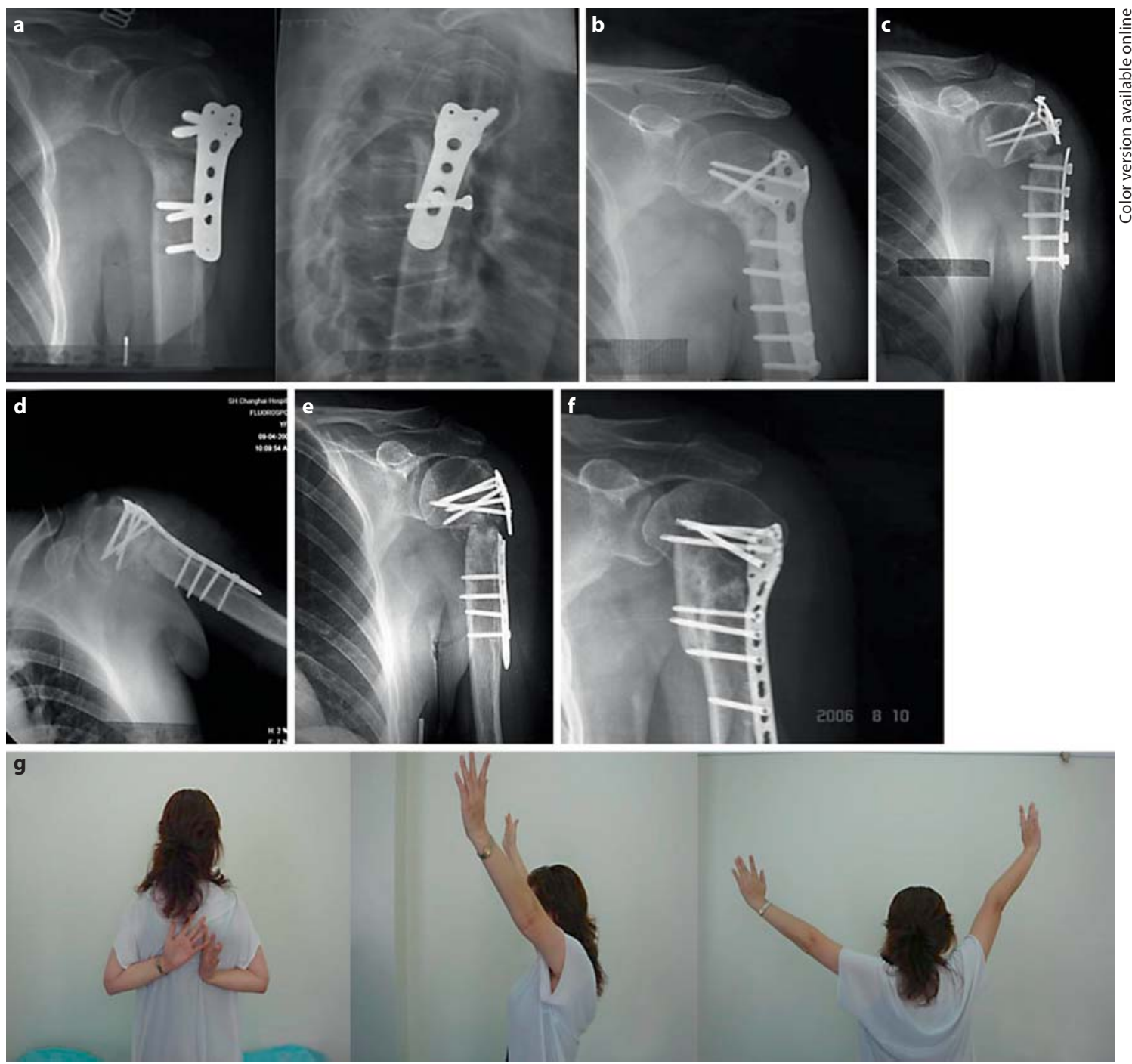

Fig. 2. Case example of a patient with recalcitrant nonunion of the surgical neck of the humerus. a Nonunion of the surgical neck of the humerus developed 18 months after surgery. b Revision surgery with cloverleaf plate fixation and autologous cancellous bone graft. c 18 months after the revision surgery, X-ray showed plate breakage and head varus deformity. $\mathbf{d}$ Second revision surgery with locked plate fixation and autologous cancellous bone graft. e X-ray showed a persistent nonunion with breakage of the locked plate 5 months after the second revision surgery. $f$ Nonunion healed 7 months after the third revision surgery with locked plate fixation and autologous fibula strut graft at the medial calcar of the humerus. The humeral head had been distorted while head necrosis was not observed. g Clinical photographs demonstrating restoration of the range of motion and return to normal activities of daily living. and active external rotation averaged $32^{\circ}$ (range 10-80). The active internal rotation averaged at the 12th thoracic vertebra (range buttock to 4 th thoracic vertebra) (fig. $2 \mathrm{~g}$ ).

The average Constant-Murley score increased from 25.7 points (range 15-35) preoperatively to 77.7 points (range 60-90) postoperatively ( $\mathrm{p}<0.001$ ). The VAS score decreased from 7.57 points (range 6-10) preoperatively to 0.57 points (range $0-2$ ) postoperatively $(\mathrm{p}<0.001)$ (table 2). All patients reported significant pain relief.
None of the patients had any postoperative infection and none of the plates or screws broke. One patient suffered partial superficial peroneal nerve palsy in the donor leg and recovered completely within 4 months. Another patient developed radial nerve palsy, which resolved within 3 months. At the final follow-up, no humeral head avascular necrosis or arthritis was observed. 
Table 2. Results

\begin{tabular}{lllll}
\hline $\begin{array}{l}\text { Patient } \\
\text { No. }\end{array}$ & $\begin{array}{l}\text { Preoperative } \\
\text { function }\end{array}$ & $\begin{array}{l}\text { Postoperative } \\
\text { function }\end{array}$ & $\begin{array}{l}\text { Preoperative } \\
\text { pain (VAS) }\end{array}$ & $\begin{array}{l}\text { Postoperative } \\
\text { pain (VAS) }\end{array}$ \\
\hline 1 & 15 & 90 & 10 & 0 \\
2 & 20 & 87 & 7 & 0 \\
3 & 40 & 82 & 8 & 0 \\
4 & 35 & 70 & 8 & 1 \\
5 & 15 & 60 & 7 & 2 \\
6 & 35 & 75 & 6 & 1 \\
7 & 20 & 80 & 7 & 0 \\
\hline
\end{tabular}

\section{Discussion}

The ideal treatment for subcapital humerus fracture nonunion is still a matter of debate. In this paper we describe an alternative technique for dealing with this nonunion.

Contemporary options for surgical neck nonunions include nailing, plating, and arthroplasty. The nailing procedure may cause a mechanical impingement and usually requires a second procedure to remove the rods [9-11]. Shoulder arthroplasty is only indicated in selected old patients or as a salvage procedure because it is important to preserve the native humeral head in young patients with relatively good bone stock $[3,5,7,12]$. The most viable fixation technique at present involves using an angle-stable device. Surgeons have achieved good results using blade plates to heal surgical neck nonunions $[1,4,13]$. Despite these results, the procedure is technically demanding, as placing a blade part inadequately in the humeral head could produce an impingement between the plate and the acromion [13].

In our study, we used the precontoured locked plate. The plate allowed us to insert a greater number of multidirectional screws into a small, poor-quality cancellous bony segment, which is often present in humeral surgical neck nonunion. Additionally, the low profile design minimized the incidence of subacromial impingement.

When nonunion of the surgical neck of the humerus occurs, the head fragment is usually in a varus malposi- tion as a result of the tension of the supraspinatus muscle [1]. In addition, an incomplete reduction at the medial hinge in association with insufficient fixation of the eggshell articular fragment often leads the head varus to slip and become impacted. Recent data suggest that locked plates cannot support the humeral head alone from a lateral position and that the integrity of the medial column is the key factor for predicting loss of fixation [14]. In the present study, we used a strut graft to reconstruct the medial calcar of the humerus. We postulate that the fibular strut may provide medial metaphyseal support, preventing varus collapse of a head.

We used autograft instead of allograft. Bone autograft is the only graft material that has osteogenic, osteoinductive and osteoconductive properties, which makes it an ideal graft material [15]. An allograft risks transmitting disease and lowers the graft's osteogenic and osteoinductive potential $[16,17]$. Regardless, surgeons should be aware that while a fibular graft may provide ideal structural support medially, it cannot restore compromised vascularization of the humeral head. Therefore, they should make great efforts to preserve the residual head vascularity intraoperatively, especially in regard to the muscular attachments to tuberosities and the posterior articular capsule. In the case described here, although the humeral head had been distorted due to multiple previous surgeries, head necrosis had not developed at last follow-up (fig. 2f).

This study is limited by the small cohort of patients, the retrospective nature of this review and the lack of a control group. It is possible, even probable, that some of them may have arthritic change developing in the affected shoulders with time. Despite these relative weaknesses, we think that this series provides important data and guidance to treat this difficult clinical problem.

\section{Conclusion}

Locked plating in combination with autologous nonvascularized fibula graft could be a simple and reliable method to treat surgical neck nonunions of the humerus.
References

\footnotetext{
1 Tauber M, Brugger A, Povacz P, Resch H: Reconstructive surgical treatment without bone grafting in nonunions of humeral surgical neck fractures. J Orthop Trauma 2011; 25:392-398.

-2 Lu CC, Chang MW, Lin GT: Intramedullary pinning with tension-band wiring for surgi-
}

cal neck fractures of the proximal humerus in elderly patients. Kaohsiung J Med Sci 2004;20:538-545.

3 Antuña SA, Sperling JW, Sánchez-Sotelo J, Cofield RH: Shoulder arthroplasty for proximal humeral nonunions. J Shoulder Elbow Surg 2002;11:114-121. 
4 Galatz LM, Williams GR Jr, Fenlin JM Jr, Ramsey ML, Iannotti JP: Outcome of open reduction and internal fixation of surgical neck nonunions of the humerus. J Orthop Trauma 2004; 18:63-67.

$>5$ Duralde XA, Flatow EL, Pollock RG, Nicholson GP, Self EB, Bigliani LU: Operative treatment of nonunions of the surgical neck of the humerus. J Shoulder Elbow Surg 1996;5:169180.

6 Walch G, Badet R, Nové-Josserand L, Levigne $\mathrm{C}$ : Nonunions of the surgical neck of the humerus: surgical treatment with an intramedullary bone peg, internal fixation, and cancellous bone grafting. J Shoulder Elbow Surg 1996;5:161-168.

$>7$ Galatz LM, Iannotti JP: Management of surgical neck nonunions. Orthop Clin North Am 2000;31:51-61.

8 Weber BG, Cech O: Pseudarthrosis: pathophysiology, biomechanics, therapy, results. New York, Grune and Stratton, 1976, pp 14 28.
9 Pospula W, Abu Noor T: Hackethal bundle nailing with intramedullary elastic nails in the treatment of two- and three-part fractures of the proximal humerus: initial experience at Al Razi Hospital, Kuwait. Med Princ Pract 2009;18:284-288.

10 Yamane S, Suenaga N, Oizumi N, Minami A: Interlocking intramedullary nailing for nonunion of the proximal humerus with the Straight Nail System. J Shoulder Elbow Surg 2008;17:755-759.

11 Lin J, Hou SM: Locked-nail treatment of humeral surgical neck nonunions. J Trauma 2003;54:530-535.

12 Badman BL, Mighell M, Kalandiak SP, Prasarn M: Proximal humeral nonunions treated with fixed-angle locked plating and an intramedullary strut allograft. J Orthop Trauma 2009;23:173-179.
13 Ring D, McKee MD, Perey BH, Jupiter JB: The use of a blade plate and autogenous cancellous bone graft in the treatment of ununited fractures of the proximal humerus. J Shoulder Elbow Surg 2001;10:501-507.

14 Gardner MJ, Weil Y, Barker JU, Kelly BT, Helfet DL, Lorich DG: The importance of medial support in locked plating of proximal humerus fractures. J Orthop Trauma 2007; 21:185-191

15 Sen MK, Miclau T: Autologous iliac crest bone graft: should it still be the gold standard for treating nonunions? Injury 2007;38:S75S80.

16 Kealey GP: Disease transmission by means of allograft. J Burn Care Rehabil 1997; 18:S10-S11.

17 Athanasiou VT, Papachristou DJ, Panagopoulos A, Saridis A, Scopa CD, Megas P: Histological comparison of autograft, allograftDBM, xenograft, and synthetic grafts in a trabecular bone defect: an experimental study in rabbits. Med Sci Monit 2010;16: BR24-BR31. 